\title{
Alq mutation increases fruit set rate and allows the maintenance of fruit yield under moderate saline conditions
}

\author{
Carlos Ribelles $^{1, \dagger}$, Begoña García-Sogo ${ }^{1, \dagger}$, Fernando J. Yuste-Lisbona, ${ }^{2}$, Alejandro Atarés ${ }^{1,(\mathbb{D})}$, \\ Laura Castañeda ${ }^{2}$, Carmen Capel $^{2}$, Rafael Lozano ${ }^{2, \mathbb{D}}$, Vicente Moreno ${ }^{1, \mathbb{D}}$ and Benito Pineda ${ }^{1, *,}$ \\ ${ }^{1}$ Instituto de Biología Molecular y Celular de Plantas (UPV-CSIC), Universitat Politècnica de València. 46022 Valencia, Spain \\ ${ }^{2}$ Centro de Investigación en Biotecnología Agroalimentaria (BITAL), Universidad de Almería, 04120 Almería, Spain \\ ${ }^{\dagger}$ These authors contributed equally to this work. \\ *Correspondence: bpineda@btc.upv.es
}

Received 20 December 2018; Editorial decision 15 July 2019; Accepted 15 July 2019

Editor: Fabrizio Costa, Fondazione Edmund Mach, Italy

\begin{abstract}
Arlequin $(A / q)$ is a gain-of-function mutant whose most relevant feature is that sepals are able to become fruit-like organs due to the ectopic expression of the ALQ-TAGL1 gene. The role of this gene in tomato fruit ripening was previously demonstrated. To discover new functional roles for ALQ-TAGL1, and most particularly its involvement in the fruit set process, a detailed characterization of $A / q$ yield-related traits was performed. Under standard conditions, the Alq mutant showed a much higher fruit set rate than the wild type. A significant percentage of $A / q$ fruits were seedless. The results showed that pollination-independent fruit set in $A / q$ is due to early transition from flower to fruit. Analysis of endogenous hormones in Alq suggests that increased content of cytokinins and decreased level of abscisic acid may account for precocious fruit set. Comparative expression analysis showed relevant changes of several genes involved in cell division, gibberellin metabolism, and the auxin signalling pathway. Since pollination-independent fruit set may be a very useful strategy for maintaining fruit production under adverse conditions, fruit set and yield in Alq plants under moderate salinity were assessed. Interestingly, Alq mutant plants showed a high yield under saline conditions, similar to that of $A l q$ and the wild type under unstressed conditions.
\end{abstract}

Keywords: ABA, ALQ-TAGL1 gene, Arlequin, cytokinins, fruit setting, salt tolerance.

\section{Introduction}

Fruit set is the most critical phase of fruit production and is of vital importance in agriculture (Mariotti et al., 2011). The transition of the ovary into a developing fruit with the capacity to become a mature organ takes place once the flower reaches the anthesis stage and is dependent on successful completion of pollination and fertilization (Gillaspy et al., 1993). The earliest phase of fruit set is characterized by a period of intense mitotic activity and involves the generation of positive signals that drive the re-activation of cell cycle-related genes (Azzi et al., 2015). MADS-box genes could function as integrators of the ovary development signal triggered by fertilization (Chevalier, 2007) since they are induced immediately after anthesis in the ovary walls (Busi et al., 2003).

This process is also regulated to a large extent by hormonal signals, especially auxins and gibberellins (GAs), and the response genes to both hormones are positively regulated after

(C) The Author(s) 2019. Published by Oxford University Press on behalf of the Society for Experimental Biology.

This is an Open Access article distributed under the terms of the Creative Commons Attribution Non-Commercial License (http://creativecommons.org/licenses/ by-nc/4.0/), which permits non-commercial re-use, distribution, and reproduction in any medium, provided the original work is properly cited. For commercial re-use, please contact journals.permissions@oup.com 
pollination (Vriezen et al., 2008; de Jong et al. 2009a; Carrera et al.,2012). In fact, application of either auxin or GA to tomato ovaries can trigger fruit set without the need for pollination and fertilization, although the effect of these hormones on cell division and cell expansion seems to be different (de Jong et al. 2009a). The application of auxin produces more cell layers in the pericarp, whereas the application of GA results in greater cell elongation, as well as reduced cell division activity in the pericarp (Serrani et al., 2007). Also, in auxin-induced fruit setting, the locular cavities are filled with jelly and the ovules do not degenerate, but form pseudoembryos. In contrast, in GA-induced fruit, the ovules degenerate and the locular tissue barely develops (de Jong et al., 2009a). It has been hypothesized that pseudoembryos can stimulate early fruit growth by producing hormones and may be able to act as a substitute for seeds in controlling fruit growth (Kataoka et al., 2003; Goetz et al., 2007; de Jong et al., 2009a).

Studies using genetic approaches in tomato and Arabidopsis have revealed that the auxin signalling pathway is instrumental in the onset of fruit development (de Jong et al. 2009a; Ruan et al., 2012). In tomato, the SlARF7 gene, a member of the tomato auxin response factor (ARF) gene family, acts as a negative regulator of fruit set and as a transcriptional activator of auxin response-attenuating genes (de Jong et al., 2009b). Down-regulation of the SIARF7 gene resulted in parthenocarpic fruit development and up-regulation of the indole3 -acetic acid (IAA)-amido synthetase gene GH3.6. The characteristics of parthenocarpic RNAi SlARF7 fruits suggest that the SIARF7 gene might be involved in the crosstalk between auxin and GA (de Jong et al., 2009b). Likewise, downregulation of SIARF5 resulted in seedless fruit development by regulating both the auxin and GA signaling pathways (Liu et al.,2018). Also the SIIAA9 gene, a member of the Aux/IAA family of tomato transcription factors, acts as a transcriptional repressor of auxin signalling (Wang et al., 2005). Silencing of SIIAA9 resulted in uncoupling fruit set from pollination and fertilization, and promoted fruit initiation in tomato (Wang et al., 2005). The SlARF8 gene plays a relevant role in regulating tomato fruit set, by stimulating expression of early auxin-responsive genes, initiating fruit growth and development (Goetz et al., 2007). It has been proposed that SIIAA9 and SlARF8 genes belong to the same signalling cascade, forming a regulatory complex that prevents fruit set prior to fertilization. Pollination and fertilization promote SIIAA9 degradation, and the SIARF8 gene is released, resulting in the transcription of the auxin response genes (Goetz et al., 2007; de Jong et al., 2009a). Mutations or transgenic manipulation of these $A R F$ and $A u x / I A A$ genes led to the development of seedless tomato fruits (Wang et al., 2005; Goetz et al., 2007; de Jong et al., 2009b; Mazzucato et al., 2015; Ueta et al., 2017). It has also been shown that, besides auxin and GA, ethylene participates in the tomato fruit set process by suppressing GA metabolism (Shinozaki et al., 2015) and promoting ovary senescence (Shinozaki et al., 2018).

Arlequin $(A l q)$ is a tomato semi-dominant mutant whose most relevant feature is that the sepals become fruits. In homozygous plants, sepal-derived fruits acquire all the characteristics of a sink and mature as normal fruits (i.e. those derived from the ovary). In addition, the fruits of Alq show much better quality parameters than those of wild-type (WT) plants and, after ripening, they do not detach because the pedicel abscission zone (AZ) is inhibited (Pineda et al., 2010). It has been demonstrated that $A l q$ mutation promotes a gain-of-function phenotype caused by the enhanced expression of the ALQTAGL1 gene (Giménez et al., 2010). Spatial and temporal expression patterns of $A L Q-T A G L 1$ in WT tomato flowers indicated that its expression begins at early stages of flower development, although the highest transcript accumulation is detected at anthesis (Giménez et al., 2010). The ALQTAGL1 gene has an essential role as a positive regulator of fruit ripening (Itkin et al., 2009; Vrebalov et al., 2009; Giménez et al., 2010), but also has additional effects on early development of the carpel, coinciding with the cell proliferation stage of carpel development following anthesis (Giovannoni et al., 2017). Overexpression of ALQ-TAGL1 results in homeotic alterations affecting floral organ identity that are similar to but stronger than those observed in Alq mutant plants (Itkin et al., 2009; Vrebalov et al., 2009; Giménez et al., 2010). It has been reported that fruits from 35S:TAGL1 plants and transgenic tomato plants overexpressing the PpPLENA gene, the peach orthologue of the ALQ-TAGL1 gene, fail to produce seeds (Tadiello et al., 2009; Vrebalov et al., 2009).

Plants developing seedless fruits usually display a higher fruit set rate under standard growth conditions. For instance, tomato transgenic lines for DefH9-RI-iaaM, a gene that increases auxin biosynthesis in ovules, yielded a higher number of fruits than the WT under standard growth conditions (Rotino et al., 2005). This is also the case for procera (pro), a parthenocarpic tomato mutant that carries a point mutation in the SIDELLA gene (Bassel et al., 2008; Jasinski et al., 2008). Compared with the WT, the pro mutant is able to develop a higher number of fruits per plant despite the fact that it develops fewer flowers (Carrera et al., 2012). Seedlessness may also improve fruit quality through increases in total soluble solids of the fruit (Ficcadenti et al., 1999; Carmi et al., 2003; Carrera et al., 2012; Mazzucato et al., 2015; Klap et al., 2017).

The pollination-dependent tomato fruit set is highly sensitive to both biotic and abiotic stresses, often leading to fruit abortion (Ruan et al., 2012). There is some evidence suggesting that pollination-independent fruit set could be useful under adverse environmental conditions (e.g. low or high temperatures), where pollination and fertilization are reduced (Carmi et al., 2003; Shabtai et al., 2007; Klap et al., 2017).

In the tomato, fruit set rate is one of the parameters of yield most affected by saline stress. Apart from the direct effects, salinity affects both pollen quantity and viability, resulting in decreased pollination-dependent tomato fruit set (Cuartero and Fernández-Muñoz, 1999; Ghanem et al., 2009). In this work, we performed a detailed assessment of fruit set in the Alq mutant. This allowed us to demonstrate that the Alq mutant exhibits an increased fruit set rate with respect to the WT. Alq mutation promotes fruit set prior to anthesis and modifies the expression pattern of genes involved in cell division, GA metabolism, and the auxin signalling pathway. Importantly, the increased fruit set rate in Alq plants allows the maintenance of yield under moderately saline conditions. 


\section{Materials and methods}

\section{Plant material}

The Arlequin tomato mutant $(A l q)$ and its genetic background have been described by Pineda et al. (2010). Tomato TAGL1-silenced (RNAi) and overexpressing (OE) lines were described by Giménez et al. (2010). Flower emasculation was carried out $2 \mathrm{~d}$ before anthesis in order to avoid accidental self-pollination. Reciprocal backcrosses by hand pollination on previously emasculated flowers were carried out with pollen collected from flowers in the anthesis stage.

\section{Pollen viability}

In vitro pollen viability assays were performed by means of staining pollen grains from $10 \mathrm{WT}$ and Alq flowers with 0.5\% 2,3,5-triphenil tetrazolium chloride (TTC) $(\mathrm{w} / \mathrm{v})$ in $0.5 \mathrm{M}$ sucrose for $2 \mathrm{~h}$ at $50{ }^{\circ} \mathrm{C}$ in a humid box in darkness and then visualized with a Leica MZZ16F light microscope (Leica Microsystems, Wetzlar, Germany). At least 200 pollen grains were scored, taking into account their colour intensity and external morphology.

\section{Ovary growth analysis}

In order to analyse the ovary growth, flowers at three floral stages (i.e. $5 \mathrm{~d}$ and $2 \mathrm{~d}$ prior to anthesis and at the anthesis stage) were collected and the three outer whorls were removed. Ovaries were viewed and measured on a stereomicroscope (MZFLIII; Leica). At least 10 flowers from two independent trials were sampled and checked for each developmental stage.

\section{Histology techniques}

Tissue sections of ovaries were fixed in FAE [ $50 \%(\mathrm{v} / \mathrm{v})$ ethanol, $5 \%(\mathrm{v} / \mathrm{v})$ formaldehyde, $10 \%(\mathrm{v} / \mathrm{v})$ acetic acid] and stored in $70 \%(\mathrm{v} / \mathrm{v})$ ethanol. Subsequently, tissues were dehydrated in $100 \%$ (v/v) ethanol and embedded in paraffin (Paraplast Plus) blocks using plastic containers. Sections of material ( $8 \mu \mathrm{m}$ thick) were cut with a Leica RM2025 microtome. The sections were stained with $0.05 \%(\mathrm{w} / \mathrm{v})$ toluidine blue for $2-5 \mathrm{~min}$ and rinsed with water. The samples were observed with a Leica MZZ16F light microscope (Leica Microsystems). The number of cell layers and cell size were measured according to the method described by Serrani et al. (2007). At least four independent sections were made from independent ovaries at the anthesis stage.

\section{Characterization of the reproductive development of WT, Alq, ALQ-TAGL1 RNAi, and ALQ-TAGL1 OE plants}

Experiments were conducted in a controlled environment greenhouse, under the following conditions: long-day photoperiod (16 h of natural light supplemented with Osram lamps Powerstar HQI-BT, $400 \mathrm{~W}$ ), temperature fixed at $24^{\circ} \mathrm{C}$ during the day and $18{ }^{\circ} \mathrm{C}$ at night, and automatic fertirrigation. Plants were irrigated daily with Hoagland's nutrient solution (Hoagland and Arnon, 1950) in 6 litre pots containing coconut fibre. Under moderate salt stress conditions, $\mathrm{NaCl}$ was added to the irrigation solution to reach $50 \mathrm{mM}$ concentration. The salt treatment was started at the sixth leaf stage and was maintained throughout the experiment. To assess fruit setting, both flowers and fruits from the first seven inflorescences of each plant were scored. To determine yield per plant, all the fruits from the first seven inflorescences were harvested and weighed.The seed number per fruit was also scored. At least 10 plants of each genotype were used in each greenhouse trial.

\section{Quantification of plant hormones}

Aliquots $(\sim 100 \mathrm{mg} \mathrm{FW})$ of frozen ovaries were extracted with $80 \%$ methanol-1\% acetic acid containing internal standards and mixed by shaking for $1 \mathrm{~h}$ at $4{ }^{\circ} \mathrm{C}$. The extract was kept at $-20{ }^{\circ} \mathrm{C}$ overnight and then centrifuged, and the supernatant was dried in a vacuum evaporator. The dry residue was dissolved in $1 \%$ acetic acid and passed through an
Oasis HLB (reverse phase) column as described in Seo et al. (2011). For GAs, IAA, and abscisic acid (ABA), the dried eluate was dissolved in $5 \%$ acetonitrile $-1 \%$ acetic acid, and the hormones were separated using an autosampler and reverse-phase UHPLC $(2.6 \mu \mathrm{m}$ Accucore RP-MS column, $50 \mathrm{~mm}$ length $\times 2.1 \mathrm{~mm}$ id; ThermoFisher Scientific) with a $5-50 \%$ acetonitrile gradient containing $0.05 \%$ acetic acid, at $400 \mu \mathrm{l}$ $\min ^{-1}$ over $14 \mathrm{~min}$. For cytokinins (CKs), the extracts were additionally passed through an Oasis MCX (cationic exchange) and eluted with 60\% methanol-5\% $\mathrm{NH}_{4} \mathrm{OH}$ to obtain the basic fraction containing CKs. The final eluate was dried and dissolved in 5\% acetonitrile-1\% acetic acid, and CKs were separated with a $5-50 \%$ acetonitrile gradient over $7 \mathrm{~min}$. The hormones were analysed with a Q-Exactive mass spectrometer (Orbitrap detector; ThermoFisher Scientific) by targeted selected ion monitoring (SIM). The concentrations of hormones in the extracts were determined using embedded calibration curves and the Xcalibur 2.2 SP1 build 48 and TraceFinder programs. The internal standards for quantification of each of the different plant hormones were the deuterium-labelled hormones.

\section{Gene expression analyses}

Total RNA was extracted from ovaries from WT and Alq plants at three stages of reproductive development: pre-anthesis (AD-2), anthesis (AD), and post-anthesis $(\mathrm{AD}+5)$. RNA preparation and gene expression studies were performed from three biological replicates according to procedures described by Giménez et al. (2010). Briefly, RNA integrity was first determined by agarose denaturing gel electrophoresis (Supplementary Fig. S3 at JXB online) and then the RNA concentration was quantified at $260 \mathrm{~nm}$ using a NanoDrop 2000 (ThermoFisher Scientific) spectrophotometer. Subsequently, first-strand cDNA was synthesized from 500 ng of total RNA using the First Strand cDNA Synthesis Kit (ThermoFisher Scientific) and an equimolar mixture of random hexamer and oligo $(\mathrm{dT})_{18}$ primers. Quantitative real-time PCRs (qRT-PCRs) were performed using gene-specific primers and the SYBR Green PCR Master Mix kit (Applied Biosystems) on the 7300 Real-Time PCR System (Applied Biosystems). Relative transcript levels were calculated using UBIQUITIN3 controls, and the quantification of gene expression were performed using the $\Delta \Delta \mathrm{Ct}$ calculation method (Winer et al., 1999). The sequences of the primers used in the expression analyses are listed in Supplementary Table S5.

\section{Results}

\section{Arlequin mutant plants have an increased fruit set rate}

Previously, we reported that the Alq mutant develops succulent sepals whose morphological features resemble tomato fruit pericarp (Pineda et al., 2010). Indeed, at the mature stage, transformed sepals from Alq homozygous plants show the characteristic red colour of tomato fruits and are able to accumulate glucose, fructose, lycopene, and carotenoids at similar levels to those of normal tomato fruits. Interestingly, the conversion of sepals into fruit-like organs is not always synchronized with ovary-derived fruit development and this process can even occur in the absence of fruit setting (Pineda et al., 2010). The fact that the ectopic expression of the ALQ-TAGL1 gene promotes the homeotic conversion of sepals into fruit-like organs suggests that this gene could play a relevant role in the ovaryderived fruit setting process.

In order to check this hypothesis, an in-depth characterization of the reproductive development of WT and Alq plants was carried out. As shown in Table 1, fruit set was significantly higher in the Alq mutant. This difference was mainly due to an increased number of fruits produced in the Alq mutant, since the number of flowers per inflorescence was similar to that of 
5734 | Ribelles et al.

Table 1. Fruit production in WT (SLDG2) and Alq plants grown under standard greenhouse conditions

\begin{tabular}{|c|c|c|c|}
\hline Parameters & & WT & $A / q$ \\
\hline Flowers per inflorescence & & $9.90 \pm 0.95 \mathrm{a}$ & $10.06 \pm 0.39 \mathrm{a}$ \\
\hline \multirow[t]{4}{*}{ Ovary-derived fruits } & Fruits per inflorescence & $4.23 \pm 0.65 b$ & $9.23 \pm 0.40 \mathrm{a}$ \\
\hline & Fruit setting rate (\%) & $42.73 \pm 5.10 b$ & $93.11 \pm 1.41 \mathrm{a}$ \\
\hline & Fruit weight (g) & $22.75 \pm 1.32 \mathrm{a}$ & $14.16 \pm 0.34 b$ \\
\hline & Yield per plant (g) & $672.68 \pm 68.98$ b & $869.65 \pm 27.70 \mathrm{a}$ \\
\hline \multirow[t]{4}{*}{ Sepal-derived fruits } & Fruits per inflorescence & ND & $9.80 \pm 0.43$ \\
\hline & Fruit setting rate (\%) & ND & $97.74 \pm 0.84$ \\
\hline & Fruit weight (g) & ND & $5.43 \pm 0.10$ \\
\hline & Yield per plant (g) & ND & $340.81 \pm 13.89$ \\
\hline \multirow[t]{4}{*}{ Ovary- and sepal-derived fruits } & Fruits per inflorescence & $4.23 \pm 0.65 b$ & $9.80 \pm 0.43 \mathrm{a}$ \\
\hline & Fruit setting rate (\%) & $42.73 \pm 5.10 b$ & $97.74 \pm 0.84 \mathrm{a}$ \\
\hline & Fruit weight (g) & $22.75 \pm 1.32 \mathrm{a}$ & $19.60 \pm 0.40 \mathrm{a}$ \\
\hline & Yield per plant (g) & $672.68 \pm 68.98 b$ & $1210.65 \pm 27.70 \mathrm{a}$ \\
\hline
\end{tabular}

Different parameters such as the number of flowers per inflorescence, number of fruits per inflorescence, fruit setting rate, fruit weight, and yield per plant were assessed, considering only ovary-derived fruits, only sepal-derived fruits, or both ovary-and sepal-derived fruit The values are given as the means \pm SD of 10 individual plants per line. Means within each column followed by different letters are significantly different in accordance with the Student's $t$-test $(P<0.05)$. ND: not detected.

the WT. In fact, considering only the ovary-derived fruits, the fruit set rate was twice as high in Alq (93\%) than in the WT $(43 \%)$. As mentioned above, mature red sepals without ovary fruit setting were also observed in $A l q$ tomato plants. Thus, considering both ovary- and sepal-derived fruits, the fruit set rate increased up to $97 \%$ in the Alq mutant (Table 1).

As expected, the highest number of fruits per inflorescence in Alq had an effect on the fruit weight, which was significantly lower than that of WT plants (Table 1). Despite that, compared with the WT, the Alq mutant showed a significantly higher yield. In this sense, yield in Alq plants was 30\% higher when only ovaryderived fruits were considered and almost $80 \%$ higher when the sepal-derived fruits were also taken into account (Table 1).

\section{The facultative parthenocarpy of Alq is not related to pollen viability loss}

The aforementioned agronomic tests indicated that Alq mutant plants produce a large number of fruits with very few seeds. On average, we were able to collect $\sim 1150 \pm 200$ seeds from a WT plant, whereas no more than $210 \pm 35$ seeds were obtained from an $\mathrm{Alq}$ plant. It was also observed that $\mathrm{Alq}$ plants develop fruits of different sizes, some being very small while others reach a caliber similar to that of WT fruits.

To clarify the reason why Alq plants produce so few seeds, we first determined the proportion of fruits with and without seeds in WT and Alq plants. Most of the Alq fruits were seedless $(73 \%)$ while only a small proportion of WT fruits (3\%) did not contain seeds (Supplementary Table S1). Notably, the characteristics of the seedless fruits were different in both cases (Fig. 1). The WT seedless fruits had a very uniform weight, ranging from $5 \mathrm{~g}$ to $7 \mathrm{~g}$, while those of the Alq mutant were very variable in weight, ranging from $3 \mathrm{~g}$ to $30 \mathrm{~g}$. In addition, the few WT seedless fruits were the so-called 'small tiny nut fruitlets' without locular jelly (Fig. 1B), whereas those of Alq contained locular jelly and seed-like structures which were smaller than the normal seeds induced by fertilization (Fig. 1C, E).
With the aim of elucidating whether the lack of viability in Alq pollen could be the cause of the seedless fruit development, pollen viability was analysed in WT and Alq flowers through in vitro and in vivo assays. The results of in vitro analyses indicated that pollen viability was not affected in Alq plants as pollen grains displayed size, morphology, and staining similar to WT pollen (Supplementary Fig. S1). In vivo analyses were performed through self-pollination by hand and reciprocal backcrosses between WT and Alq plants. No differences were observed in the weight and number of seeds of WT and Alq fruits obtained by self-fertilization (Supplementary Table S2). Similarly, both backcrosses yielded fruits of similar size, and the average seed number using WT pollen was not significantly different from the average seed number with $A l_{q}$ pollen (Supplementary Table S2). Overall, the results showed that seedless fruit development in $A l q$ plants is not related to the absence of pollen viability as, when successful pollination and fertilization of the ovules occur, Alq fruits are able to reach the same weight and develop the same number of seeds as WT fruits.

\section{Alq ovaries exhibit precocious fruit set}

In normal development, fruit set is dependent on successful completion of pollination and fertilization, and the starting point of this process is the flower anthesis stage (Gillaspy et al., 1993). A few days before anthesis, the ovary enters into an 'arrest' state and, when fertilization is successfully completed, the ovary resumes growth (Klap et al., 2017).

The results mentioned above indicated that the process of fruit setting in the Alq mutant is not pollination dependent and that its facultative parthenocarpy is not related to the lack of pollen viability. To assess possible early fruit development in Alq plants, we examined the ovary size in three flower stages: $5 \mathrm{~d}$ and $2 \mathrm{~d}$ prior to anthesis, and the anthesis stage. There were no significant differences in size between WT and Alq ovaries at either $5 \mathrm{~d}$ or $2 \mathrm{~d}$ before anthesis (Fig. 2A). However, the 


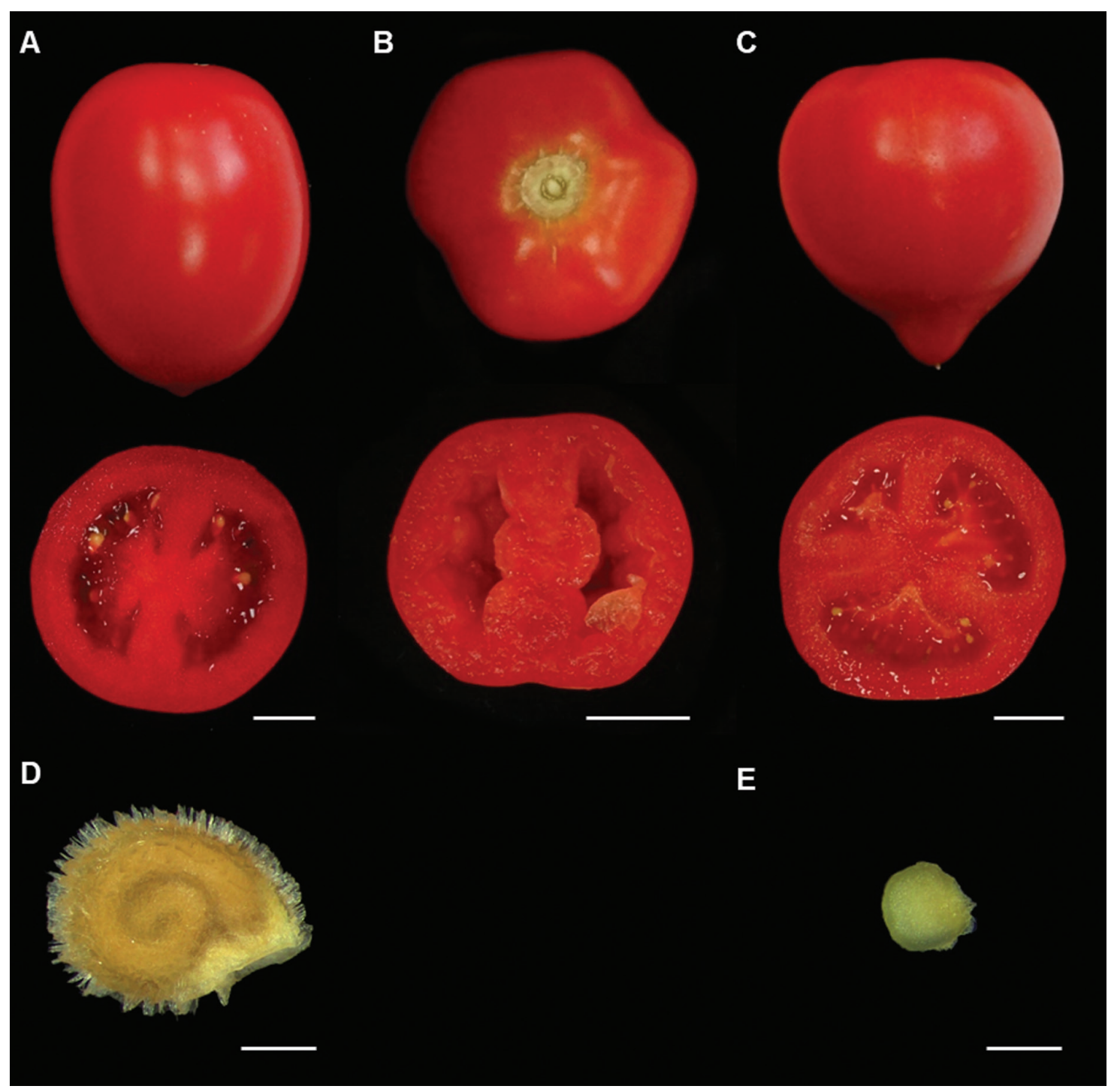

Fig. 1. Characteristics of mature fruits and seeds from WT and Alq plants. (A) WT seeded fruits. (B) WT seedless fruits. (C) Alq seedless fruits. (D) Seed from a WT fruit. (E) Seed-like structure from an Alq fruit. Scale bars: $1 \mathrm{~cm}$ in $(A-C)$ and $1 \mathrm{~mm}$ in (D) and (E).

results showed a significant increase in the average size of Alq ovaries at anthesis $(2.37 \pm 0.05 \mathrm{~mm})$ with respect to the WT $(2.01 \pm 0.04 \mathrm{~mm})$, which means an increase of $\sim 18 \%$ in the ovary size. To gain more insight into this feature, cross-sections of WT and Alq ovaries at anthesis were examined by light microscopy. We observed that the pericarp thickness of Alq ovaries was higher than that of the WT (Fig. 2B, C). Interestingly, the increase of pericarp thickness was associated with a significantly higher number of cell layers (Fig. 2C). WT and Alq pericarp cells were similar in size (Fig. 2C), suggesting that the larger size of the ovary in Alq flowers at the anthesis stage resulted from greater cell division rather than greater cell expansion.

To fully determine whether Alq flowers are actually able to develop into fruits in a pollination-independent way, flowers were emasculated at the pre-anthesis stage and tested for both ovary- and sepal-derived fruit setting. All the WT emasculated flowers aborted, whereas $>45 \%$ of the Alq emasculated flowers were able to set ovary-derived fruits. In addition, nearly $80 \%$ of the emasculated flowers of Alq plants set sepal-derived fruits (SupplementaryTable S3; Supplementary Fig. S2). Taken as a whole, the results indicate that the Alq mutant is able to set fruits in a pollination-independent way and that its facultative parthenocarpy is due to an early transition from flower to fruit.

\section{Changes in endogenous hormone levels may account for early fruit set in the Alq mutant}

Endogenous hormone analysis in the Alq mutant showed a higher level of $\mathrm{GA}_{1}$ at the anthesis stage combined with a lower level of ABA at both $5 \mathrm{~d}$ and $2 \mathrm{~d}$ before anthesis (Fig. $3 \mathrm{~A}, \mathrm{C})$. Furthermore, the Alq mutant showed a significantly higher level of different CKs at most of the floral stages analysed. Indeed, dihydrozeatin (DHZ) concentration significantly increased at both $5 \mathrm{~d}$ and $2 \mathrm{~d}$ before anthesis; the same happened with isopentenyladenine (iP) at $5 \mathrm{~d}$ before anthesis, and trans-zeatin ( $\mathrm{tZ}$ ) significantly increased at all floral stages analysed (Fig. 3E-G). These hormonal changes, especially the higher CK concentration at floral stages prior to anthesis, may account for the early transition from flower to fruit in the Alq mutant as well as for its ability to develop seedless fruits. 
(A)

(B)
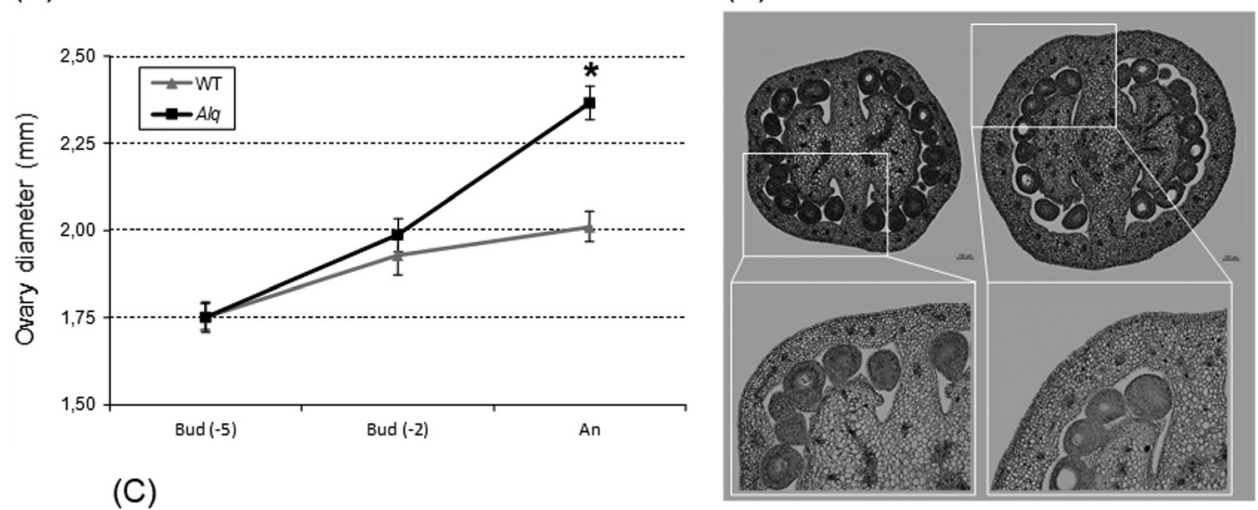

\begin{tabular}{lcc}
\hline Parameters & WT & Alq \\
\hline Pericarp thickness $(\mu \mathrm{m})$ & $102,56 \pm 3,28(\mathrm{~b})$ & $184,75 \pm 5,79(\mathrm{a})$ \\
Pericarp cell layers $(\mathrm{n})$ & $9,93 \pm 0,15(\mathrm{~b})$ & $14,15 \pm 0,17(\mathrm{a})$ \\
Pericarp cell size $(\mu \mathrm{m})$ & $18,05 \pm 0,29(\mathrm{a})$ & $18,16 \pm 0,27(\mathrm{a})$ \\
\hline
\end{tabular}

Fig. 2. Precocious fruit setting in Alq ovaries. (A) Comparison of WT and Alq ovary diameter in three stages of floral development: $5 \mathrm{~d}$ before anthesis [Bud (-5)], 2 d before anthesis [Bud (-2)], and anthesis day (An). (B) Cross-sections of ovary pericarp in WT (left) and Alq (right) flowers at the anthesis stage. (C) Thickness, cell layers, and cell size in pericarp of WT and Alq ovaries at the anthesis stage. The values are given as the mean \pm SE. In (A), error bars represent \pm SE of two independent trials; for each trial, $n \geq 10$. The statistical significance of mean differences was analysed using Fisher's test $(P \leq 0.05)$. Asterisks or different letters indicate statistical significance $(P \leq 0.05)$.

The Alq mutation modifies the expression pattern of tomato genes involved in different processes related to fruit set

Comparative expression analyses were carried out in order to analyse genetic interactions of the Alq mutation with tomato genes involved in fruit set and reproductive development. Flowers collected at three developmental stages $(2 \mathrm{~d}$ before anthesis, at anthesis, and $5 \mathrm{~d}$ post-anthesis) were chosen for comparative analysis between the pericarp tissue of WT and Alq plants.

The transcript levels of some genes involved in GA biosynthesis (SlGA20ox1, SlGA20ox2,SlGA20ox3, SlGA3ox1, and $S l G A 3 \circ \times 2)$ and GA inactivation (SlGA2ox1 and SlGA2ox2) were analysed. Although significant differences in the expression levels of most of the SlGA20ox genes were not detected, the expression of the SlGA200x1 and SlGA20ox3 genes was significantly down-regulated in the $A l q$ ovary at postanthesis and the anthesis stage, respectively (Supplementary Fig. S4C, E). However, transcript levels of both SlGA30x1 and $S I G A 30 \times 2$ were significantly increased at the pre-anthesis stage (Supplementary Fig. S4A, B). In the case of the GA2oxidases, no significant changes in transcript levels were observed in the $S l G A 20 \times 1$ gene, whereas the $S l G A 20 \times 2$ gene was up-regulated at pre-anthesis and anthesis stages in Alq ovaries (Supplementary Fig. S4F, G).

The expression of some auxin signalling genes (SIIAA9, SIARF5, SIARF7, and SIARF8) known to be involved in the control of fruit initiation was also analysed. The transcript levels of the IAA9 gene were similar in WT and Alq ovaries (Supplementary Fig. S5A). Concerning the SlARF5 gene, no significant changes in transcript levels were observed at either pre-anthesis or anthesis stages, but significant differences in the expression levels were detected at the post-anthesis stage (Supplementary Fig. S5B). Transcript levels of SlARF7 and SIARF8 shared similar patterns and showed a significant up-regulation in Alq ovaries, at both pre-anthesis and anthesis stages (Supplementary Fig. S5C, D).

The transcript levels of some genes involved in ethylene biosynthesis (SlACO1, SlACO2, SlACO3, SlACS1A, and SlACS6) and senescence (SlSAG12 and SINAP) were also analysed. Significant differences in the expression levels of these genes were not detected at pre-anthesis and anthesis stages, except in the case of the SIACS1A gene that was significantly up-regulated at the anthesis stage (Supplementary Fig. S6D). However, transcript levels of SlACO1, SlACO2, SlACO3, SlACS1A, SlACS6, SlSAG12, and SINAP genes were significantly increased at the post-anthesis stage (Supplementary Fig. S6A-G).

As the fruit set process requires an intense cell division activity, transcript levels of some genes involved in the cell cycle $(C \gamma c A 1, C \gamma c D 3$, and $C D K A 1)$ and cell division control (SlWUS) were also analysed. In $A l q$ ovaries, the $C \gamma c A 1$ gene was down-regulated at the post-anthesis stage, and the same occurred with the $C y c D 3$ gene at both anthesis and postanthesis stages (Fig. 4A, B). Importantly, the CDKA1 gene was significantly up-regulated at both anthesis and post-anthesis in Alq ovaries (Fig. 4C). In addition, a significant up-regulation of the SlWUS gene was detected in Alq ovaries at all the floral stages analysed (Fig. 4D). The results of cell cycle gene expression levels are consistent with the changes detected in the content of endogenous hormones, especially CKs, and the early ovary to fruit transition. 
A

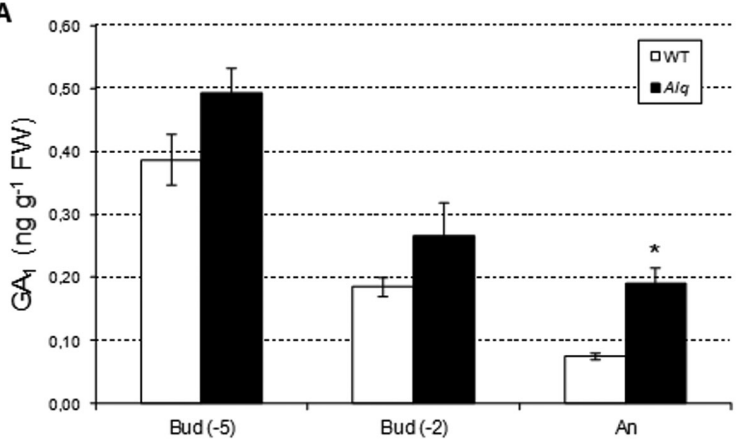

C

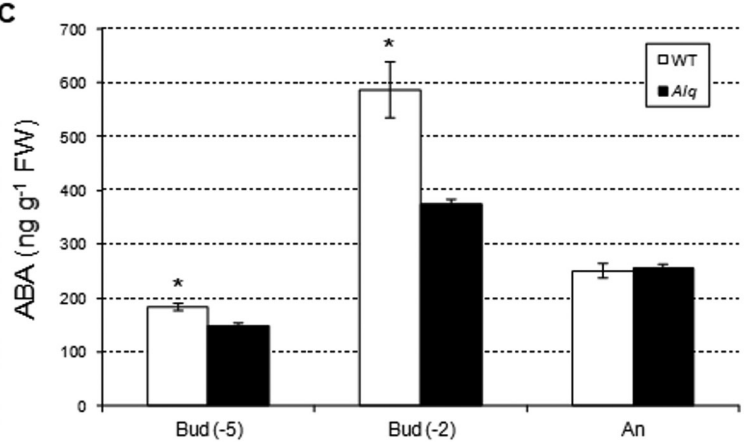

E

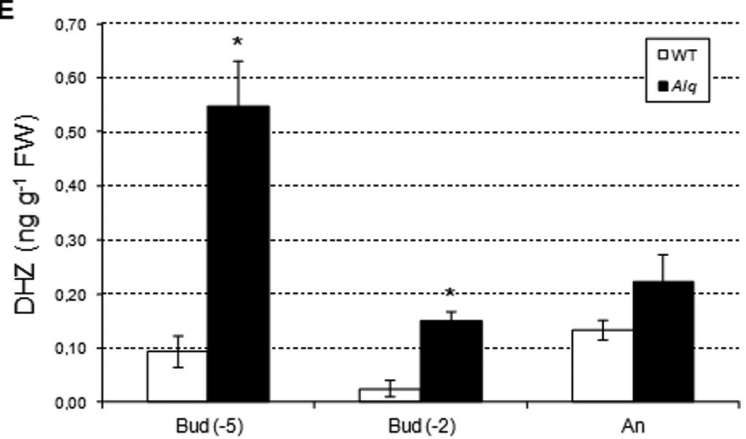

G

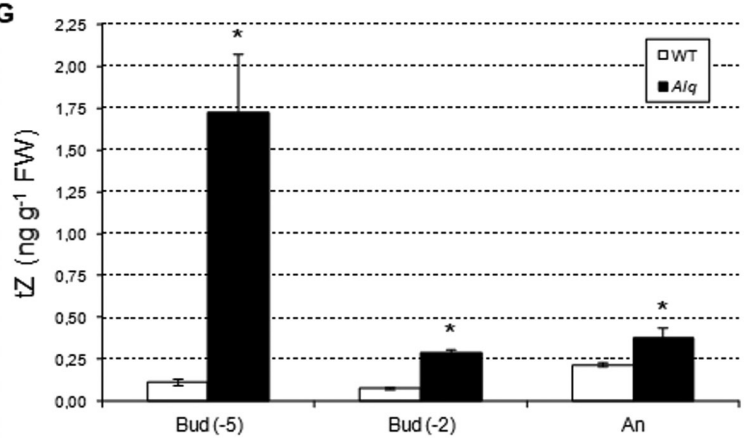

B

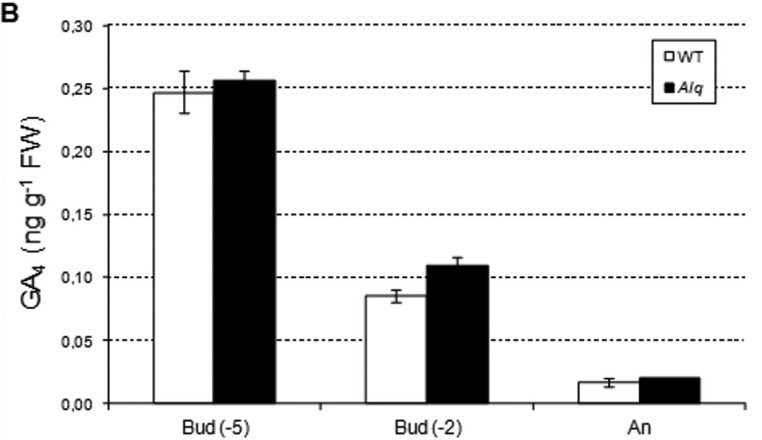

D

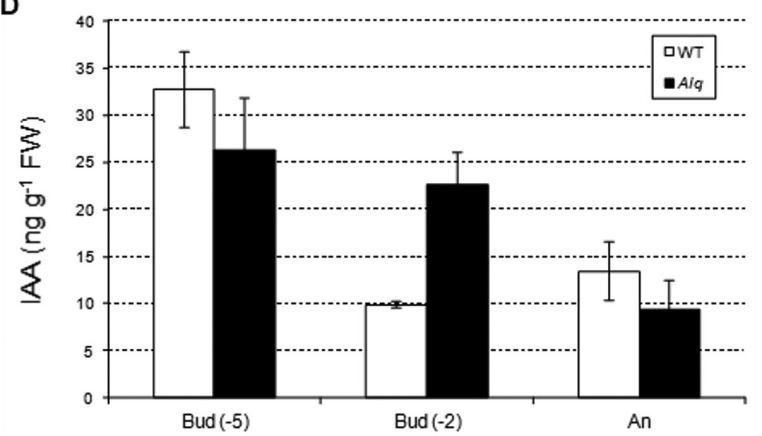

F

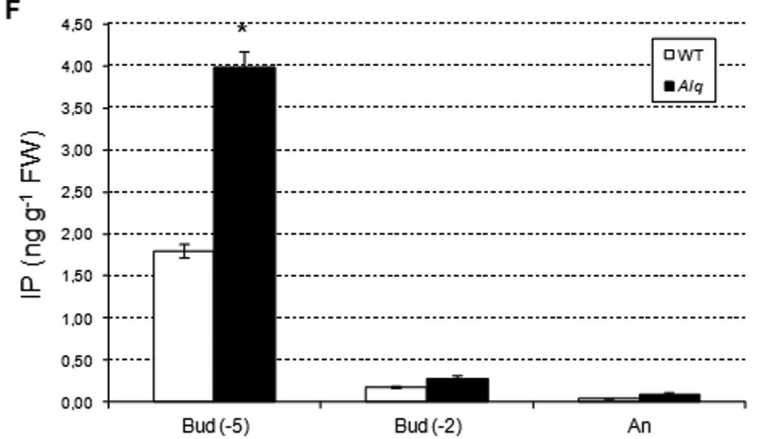

Fig. 3. Endogenous level of different hormones in ovaries from WT and Alq plants. The analysis was performed on entire ovaries at 5 days before anthesis [Bud (-5)], 2 d before anthesis [Bud (-2)], and anthesis day (An). (A, B) GA 1 and $\mathrm{GA}_{4}$ : gibberellins GA 1 and GA 4 , (C) ABA: abscisic acid, (D) IAA: indole-3-acetic acid, (E) DHZ: dihydrozeatin, (F) IP: isopentenyladenine; and (G) tZ: trans-zeatin. The results show the averages and standard errors of three biological replicates (aliquots of $\sim 100 \mathrm{mg}$ each). Asterisks indicate significant differences (Student's $t$-test, $P \leq 0.05$ ). 
A

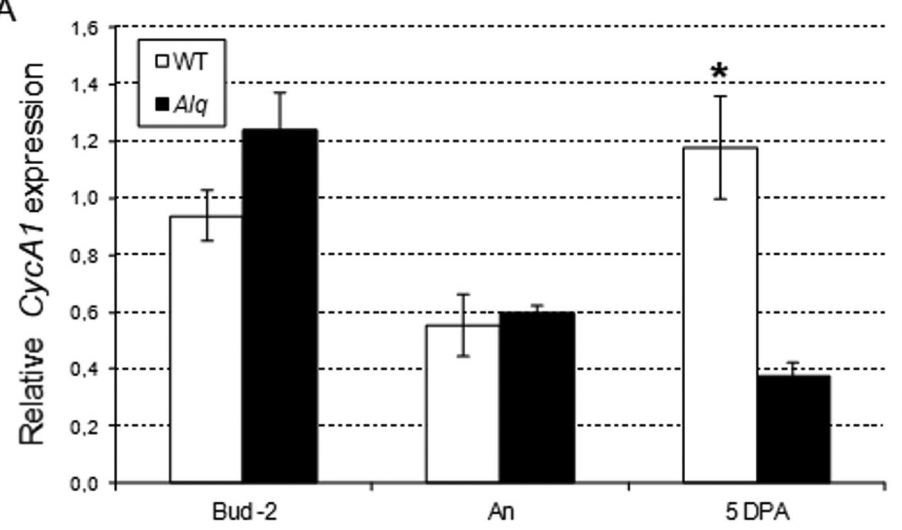

C

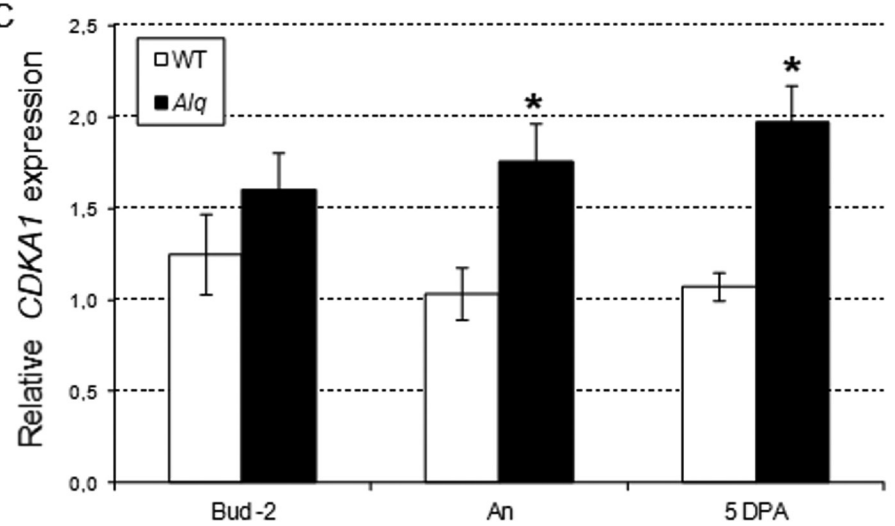

B

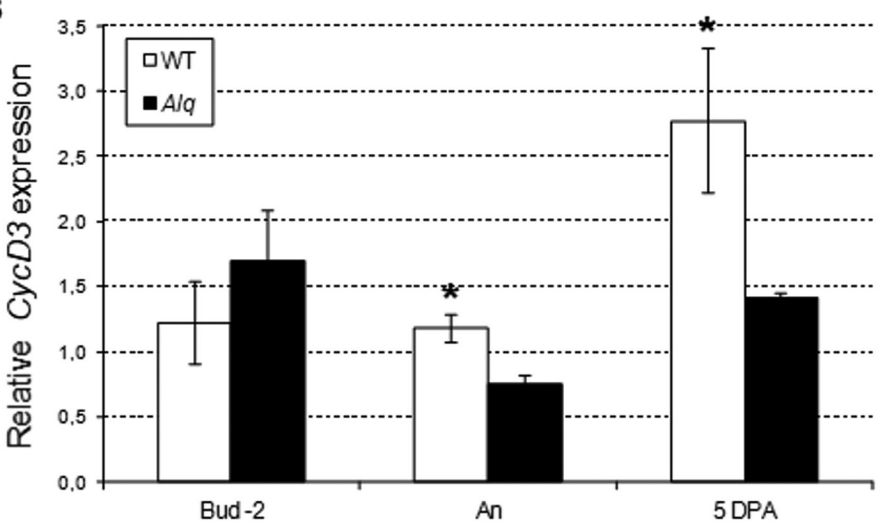

D

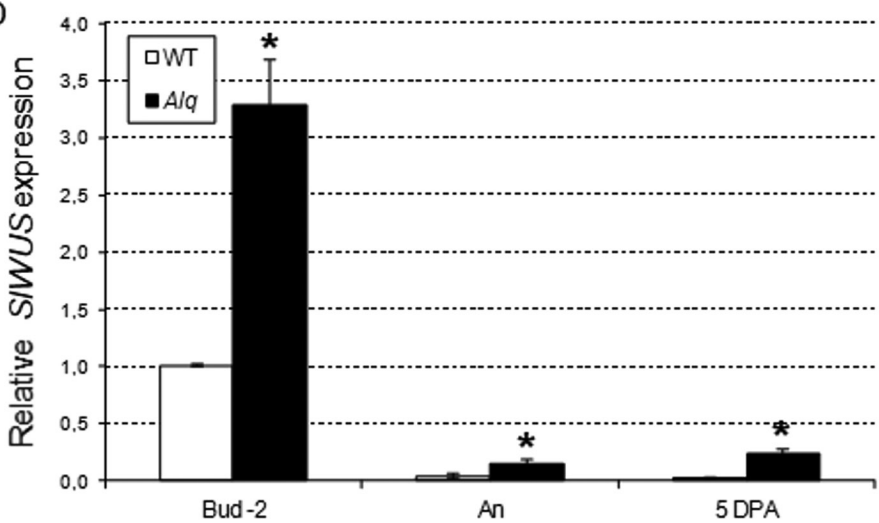

Fig. 4. Expression analyses of tomato genes involved in cell cycle (A-C) and cell division control (D). CycA1 (A), CycD3 (B), CDKA1 (C), and SIWUS (D) gene expression in WT and Alq ovaries in three stages of floral development: $2 \mathrm{~d}$ before anthesis [Bud (-2)], anthesis day (An), and $5 \mathrm{~d}$ post-anthesis (5 DPA). The results show the averages and standard errors of three independent biological experiments and three technical replicates. Asterisks denote significant differences (Student's $t$-test, $P<0.05)$.

\section{Alq plants are able to maintain fruit yield under moderate salinity conditions}

Fruit set and yield of WT and Alq plants were assessed under both control and moderate salt stress conditions. Plants were grown in a greenhouse without and with salt stress $(50 \mathrm{mM}$ $\mathrm{NaCl}$ ) applied from the sixth leaf stage and maintained throughout the experiment.

In WT plants, the numbers of flowers and fruits per inflorescence were significantly lower in salt stress with respect to control conditions. In contrast, in Alq plants, no differences were found in both parameters when comparing control and stress conditions (Table 2). Notably, in both control and salt stress conditions, the number of fruits per inflorescence was significantly higher in Alq than in WT plants (Table 2; Supplementary Fig. S7). Likewise, fruit set rate was significantly higher in Alq plants, reaching 75\% in control conditions and $84 \%$ under moderate salt stress. In fact, the two-way ANOVA indicated that the only relevant factor for fruit set was the line. As observed in previous experiments carried out under normal conditions, the average fruit weight was lower in Alq than in the WT. However, under stress conditions, the reduction in fruit weight was greater in the WT (38\%) than in Alq (29\%) (Supplementary Table S4). Indeed, as shown in Fig. $5 \mathrm{~A}$, almost half of the fruits produced by WT plants in control conditions had a weight $\geq 50 \mathrm{~g}$, the other half ranged from $20 \mathrm{~g}$ to $50 \mathrm{~g}$, and a small proportion weighed $<20 \mathrm{~g}$. In salinity conditions only $3 \%$ of the fruits produced by WT plants had a weight $\geq 50 \mathrm{~g}$, almost $75 \%$ ranged from $20 \mathrm{~g}$ to $50 \mathrm{~g}$, and $>20 \%$ weighed $<20 \mathrm{~g}$. Thus, significant differences were found in all the weight ranges in the case of WT plants (Fig. 5A). In contrast, no significant differences were found when comparing these weight ranges in Alq fruits (Fig. 5B, C).

In the WT, fruit yield per plant under salt stress was significantly lower $(599.4 \mathrm{~g})$ than in control conditions (1097.6 g) (Table 2), representing a yield decline of $>45 \%$ (Supplementary Table S4). In contrast, Alq plants were able to maintain fruit yield under moderate salinity conditions. Thus, when only ovary-derived fruits were taken into account, fruit yield per plant in Alq plants reached $928.7 \mathrm{~g}$ in control conditions and 834.9 under salt stress, which represents a yield decline of just $10 \%$. When both ovary- and sepal-derived fruits were taken into account, fruit yield increased up to $1170.6 \mathrm{~g}$ in control conditions and 1051.8 under salt stress (Table 2). From an agronomic point of view, it is noteworthy that in both cases fruit yield in Alq plants was not significantly reduced by salinity.

\section{Fruit setting decreases in ALQ-TAGL1-down-regulated plants and increases in plants overexpressing ALQ-TAGL1}

To further validate the effect of the ALQ-TAGL1 gene on fruit set, we evaluated yield parameters under both control and moderate salt conditions in plants in which ALQ-TAGL1 


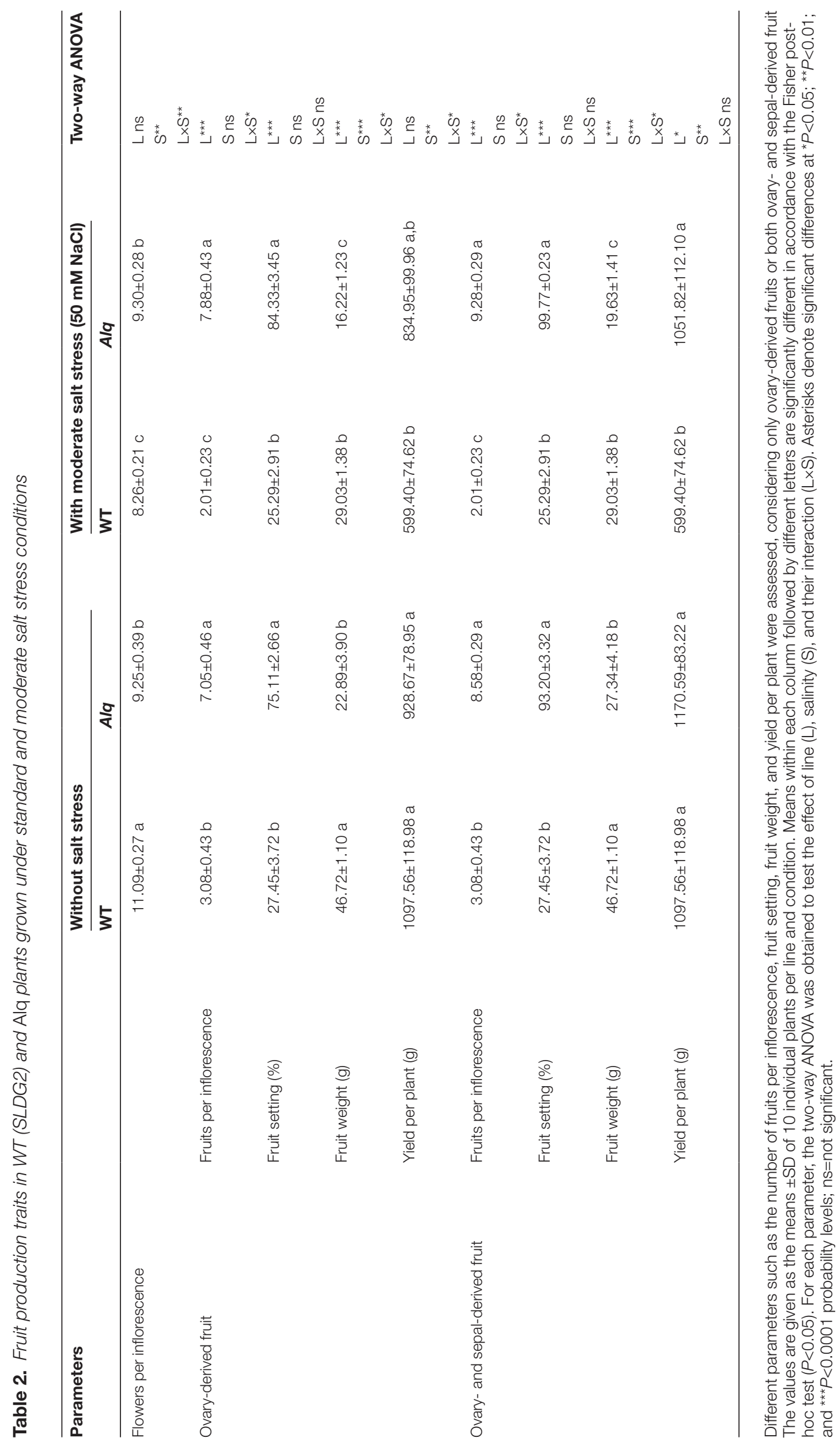



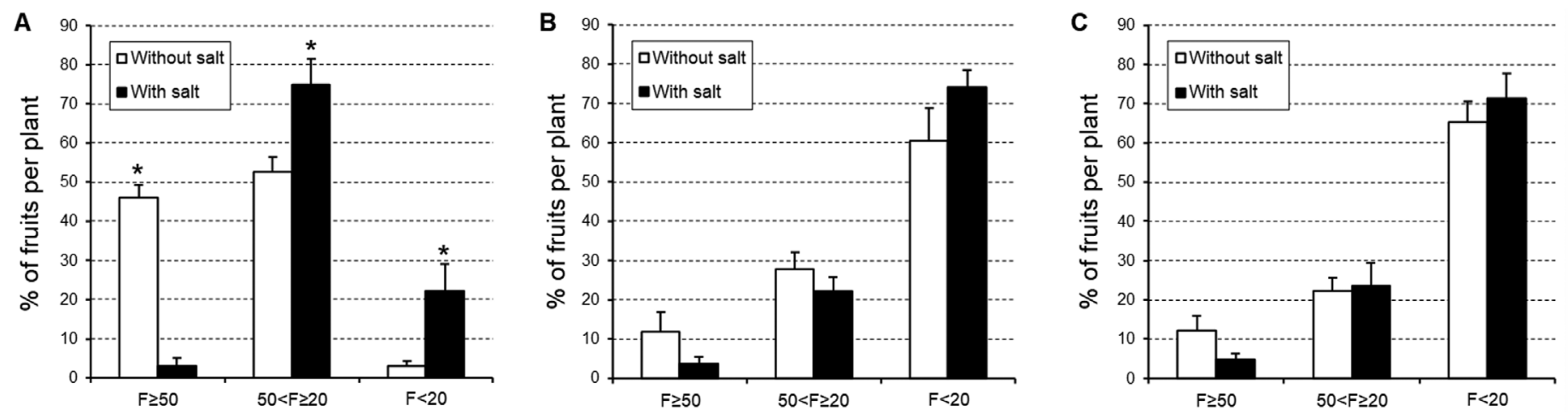

Fig. 5. Percentage of fruit per weight interval in both non-salt and salt conditions: (A) WT, (B) Alq (ovary-derived fruits), and (C) Alq (ovary- and sepalderived fruits). Each graph illustrates the percentage of fruits whose weights are $\geq 50 \mathrm{~g}(\mathrm{~F} \geq 50)$, with weights between $20 \mathrm{~g}$ and $50 \mathrm{~g}(50<\mathrm{F} \geq 20)$, and with weights $<20 \mathrm{~g}(\mathrm{~F}<20)$. A total of 118 and $125 \mathrm{WT}$ fruits, 220 and $255 \mathrm{Alq}$ fruits (ovary-derived fruits), and 281 and 320 Alq fruits (ovary- and sepal-derived fruits) from non-salt and salt conditions, respectively, were used. Asterisks indicate significant differences (Student's $t$-test, $P \leq 0.05)$.

was silenced or overexpressed. In both WT and ALQ-TAGL1RNAi plants, fruit yield per plant under salt stress was significantly lower than in control conditions, representing a yield decline of $55 \%$ and $69 \%$, respectively. However, no significant differences were found in ALQ-TAGL1-OE plants when comparing fruit yield under both conditions (Table 3). With respect to fruit set, a significant decline was observed under control conditions in the ALQ-TAGL1-RNAi plants, despite the fact that the number of flowers per inflorescence was lower than in WT plants. Importantly, set rate was significantly higher in ALQ-TAGL1-OE plants under both control conditions and moderate salt stress (Table 3). Consistent with these results, the two-way ANOVA indicated that the only relevant factor for fruit set was the line.

\section{Discussion}

Arlequin (Alq) is an insertion mutant whose sepals have the outstanding ability to turn, morphologically, structurally, and metabolically, into fruit-like organs which acquire all the characteristics of a sink and ripen as in ovary-derived fruits (Pineda et al., 2010). Molecular characterization of the tagged gene demonstrated that $A l q$ is a gain-of-function mutant and that its characteristic phenotype is due to the ectopic expression of the ALQ-TAGL1 gene (Giménez et al., 2010). The essential role of this gene as a positive regulator of fruit ripening has been shown (Itkin et al., 2009; Vrebalov et al., 2009; Giménez et al., 2010). Several lines of evidence suggested that this gene may also play an important role in the fruit setting process. The highest accumulation of transcripts occurs 1-2 d before anthesis, at the anthesis stage (Giménez et al., 2010), or immediately after in the ovary (Busi et al., 2003). It has also been stated that the ALQ-TAGL1 gene plays a role in the cell proliferation stage following anthesis (Giovannoni et al., 2017). Furthermore, the fact that the ectopic expression of ALQ-TAGL1 in the Alq mutant causes a homeotic conversion of sepals into functionally equivalent structures to carpels points in the same direction. Therefore, the ALQ-TAGL1 gene could emerge as a new player in the fruit set process.

We present here compelling evidence in this respect, since the in-depth characterization of the reproductive development of Alq revealed that the up-regulation of the ALQ-TAGL1 gene, caused by the T-DNA insert, doubles the fruit set rate (93\% in Alq versus 43\% in the WT, Table 1). The enhanced expression of the ALQ-TAGL1 gene in Alq not only increases the fruit set rate but also promotes the ability to set fruits in a pollination-independent way (Fig. 1C; Supplementary Table S1). Notably, it has been reported that the overexpression of the PPPLENA gene, the peach orthologue of ALQ-TAGL1, also promotes pollination-independent fruit set in transgenic tomato plants (Tadiello et al., 2009). Unlike that which occurs in other mutants with facultative parthenocarpy (Mazzucato et al., 1998; Rojas-Gracia et al., 2017), in vitro and in vivo tests have shown that the ability of Alq to set fruits in the absence of pollination is not related to the lack of pollen viability (Supplementary Fig. S1; Supplementary Table S2). Instead, the parthenocarpic fruit development in $A l q$ is due to precocious fruit set prior to anthesis (Fig. 2). Most of the Alq seedless fruits bore seed-like structures, usually called pseudoembryos or aborted seeds (Fig. 1E). These pseudoembryos are typically present in auxin-induced fruits (Asahira et al., 1967; Kataoka et al., 2003), but have also been found in parthenocarpic tomato fruits treated with synthetic CKs (Matsuo et al., 2012). Pseudoembryos in seedless fruits have also been observed in transgenic tomatoes expressing an aberrant form of AtARF8, an ARF expressed in the ovule (Goetz et al., 2007). Similarly, in the ovules of WT flowers at stage 9 (according to Brukhin et al., 2003), high levels of ALQ-TAGL1 transcripts have been found (Vrebalov et al., 2009; Giménez et al., 2010). Therefore, it cannot be ruled out that enhanced expression of $A L Q-$ TAGL1, through the stimulation of SIARF8 gene expression, takes part in the development of the pseudoembryos observed in $A l q$ fruits.

Our results indicated that the enhanced expression of the ALQ-TAGL1 gene in Alq increases the expression of some ethylene-related genes at the post-anthesis stage (Supplementary Fig. S6A-E), consistent with the fact that the ALQ-TAGL1 gene acts upstream of ethylene-related genes (Itkin et al., 2009; Vrebalov et al., 2009; Giménez et al., 2010). Ethylene is involved in ovule senescence in unpollinated ovaries (Shinozaki et al., 2018). The higher expression levels of both SISAG12 and SINAP genes observed in Alq ovaries at the post-anthesis 


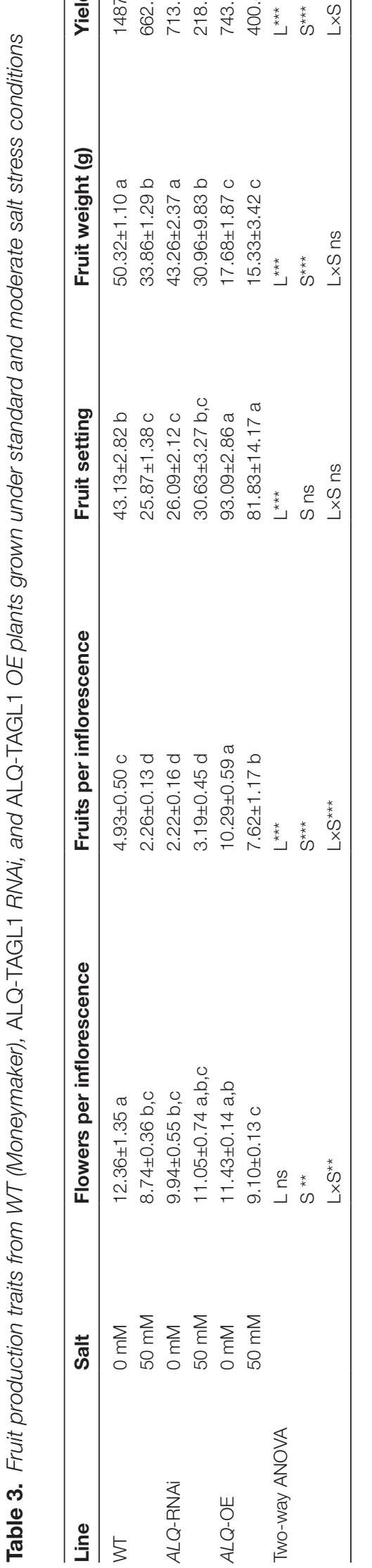

stage (Supplementary Fig. S6F, G) could be associated with the senescence of the ovules, since the Alq mutation promotes pollination-independent fruit set.

Besides GAs and auxins, CKs and ABA are generally believed to be involved in fruit growth and development (Mariotti et al., 2011). The levels of auxin, GAs, and CKs increase during the fruit setting phase, while those of ABA decrease (Mariotti et al., 2011; McAtee et al., 2013; Kumar et al., 2014). The exogenous application of auxin and GAs can trigger pollination-independent fruit set in tomato plants (Martí et al., 2007; Serrani et al., 2007, Matsuo et al., 2012). Similarly, exogenous CK treatment has been reported to induce parthenocarpy in the tomato (Ding et al., 2013) and it has been proposed that its endogenous level is directly correlated with fruit growth, especially in the stimulation of cell division (Kumar et al., 2014). Marsch-Martínez et al. (2012) demonstrated that SHATTERPROOF (SHP) MADS-box transcription factor genes, the Arabidopsis orthologues of the ALQ-TAGL1 gene, are required for CK accumulation during gynoecium and fruit development. More importantly, the concentrations of different CKs (DHZ, iP, and tZ) significantly increased before anthesis, coinciding with the time when fruit set in Alq occurs (Fig. 3E-G). Our results suggest that the increase of endogenous CKs promoted by the up-regulation of the ALQ-TAGL1 gene is one of the factors that determine early fruit set in Alq, possibly through the activation of core cell cycle genes during the early stages of fruit development. On the other hand, the role of ABA in the tomato fruit set process is still unclear. Nitsch et al. (2009) showed that ABA levels are relatively high in mature ovaries and down-regulated after pollination, which suggests that $\mathrm{ABA}$ inhibits ovary growth until fruit set. However, it was not possible to induce fruit set by way of the application of an ABA biosynthesis inhibitor (fluridone) nor to inhibit fruit set by ABA application to pollinated ovaries. For this reason, these authors suggested that $\mathrm{ABA}$ is an additional player in the regulation of tomato fruit set, together with other hormones. Our results provide evidence in favour of this hypothesis. The analysis of endogenous hormones in Alq ovaries not only showed a dramatic increase in CK content but also a significantly lower level of ABA at both $5 \mathrm{~d}$ and $2 \mathrm{~d}$ before anthesis (Fig. 3C). This could indicate that it is not just the concentration of either CKs or ABA, but rather the $\mathrm{CK}$ and $\mathrm{ABA}$ crosstalk, that is the key event which induces early fruit set in the Alq mutant.

Our results also showed that $A l q$ ovaries had higher pericarp thickness mainly associated with an increase in cell layers at anthesis (Fig. 2B, C). Tomato fruit development is characterized by an intense activity of cell divisions after the fruit set. As mentioned above, the endogenous level of CK is directly correlated with the fruit growth, especially in the stimulation of cell division (Kumar et al., 2014). Furthermore, the active cell division induced upon flower fertilization is consistent with the up-regulation of CDKs (Joubès et al., 1999). Comparative expression analyses in the Alq mutant revealed important changes in transcript levels of several genes involved in cell division, GA metabolism, and the auxin signalling pathway (Fig. 4; Supplementary Fig. S4; Supplementary Fig. S5). In tomato ovaries, CDKA1 transcripts accumulate after anthesis 
(Joubès et al., 1999). The significantly higher expression levels of the CDKA1 gene observed in $A l q$ ovaries at the anthesis stage could be associated with the early ovary growth (Fig. 4C). This precocious ovary growth in the Alq mutant could also be related to the up-regulation of genes encoding enzymes of GA biosynthesis (SlGA3ox1 and SlGA3ox2) before the anthesis stage (Supplementary Fig. S4A, B). Moreover, Alq mutation influences the expression pattern of some auxin signalling pathway components that have been shown to be instrumental in the control of tomato fruit initiation. SIARF8, a member of the tomato $A R F$ gene family, can stimulate expression of early auxin-responsive genes, initiating fruit growth and development (Goetz et al., 2007). In fact, tomato transgenic plants down-regulated in the expression of the SIIAA9 gene exhibited precocious fruit set and showed up-regulation of SIARF8 at the bud stage (Wang et al., 2005, 2009). Interestingly, the SIARF8 gene showed strong up-regulation in Alq ovaries at pre-anthesis and anthesis stages (Supplementary Fig. S5D), although no significant changes were detected in the expression of the SIIAA9 gene (Supplementary Fig. S5A). SlARF5, another member of the tomato $A R F$ gene family, is expressed at high levels in unpollinated ovaries but maintains low expression levels in pollinated ovaries (Liu et al., 2018). The higher expression levels of the SlARF5 gene observed in Alq ovaries post-anthesis could be associated with the pollinationindependent ovary growth (Supplementary Fig. S5B). Also, the SlWUS gene, which is a member of the plant-specific WUS homeobox (WOX) transcription factor family (Muños et al., 2011) and is involved in promotion of cell division (Azzi, et al., 2015), was significantly up-regulated from the pre-anthesis stage (Fig. 4D). Apart from its important role in the ripening process (Itkin et al., 2009; Vrebalov et al., 2009; Giménez et al., 2010), it has been documented that the ALQ-TAGL1 gene is involved in the regulation of fruit development through cell division control (Azzi et al., 2015). Therefore, the higher expression of ALQ-TAGL1 in the Alq mutant could promote pollination-independent ovary growth by altering transcript levels of genes involved in cell division and other important regulators related to fruit setting. Interestingly, our results indicated that in the Alq mutant, there is an increase in the expression of cell cycle genes in the ovary of flowers at the anthesis stage as well as in the early stages of fruit development (Fig. 4C). Moreover, fruit setting is significantly reduced in $A L Q-$ TAGL1-silenced plants and increased in plants overexpressing ALQ-TAGL1 (Table 3). These results suggest that the ALQTAGL1 gene could act as an integrator of the ovary development signal in the fruit set process.

The ability of the Alq mutation to increase the fruit set rate could be of potential interest under unfavourable stress conditions. In this study, a comparative assessment of the fruit set and yield under both standard and moderate salt stress conditions was carried out in WT and Alq plants (Table 2). According to Cuartero and Muñoz (1999), at relatively low salinity electrical conductivities (e.g. $2.5 \mathrm{dS} \mathrm{m}^{-1}$ ), the yield reduction is mainly caused by a decrease in the fruit average weight. Interestingly, we have observed that salt stress had a more severe impact on fruit weight of the WT than of Alq. In addition, WT plants cultivated under salt conditions significantly reduced the percentage of larger fruits and significantly increased the percentage of smaller ones. In contrast, in Alq plants the percentage of larger and smaller fruits was similar under standard and salt conditions (Fig. 5). Under non-salt conditions, most of the Alq flowers set fruit, while only one out of four flowers of WT plants did. Notably, under salt conditions, Alq plants developed a similar number of fruits to that in normal conditions, whereas in WT plants the number of fruits per inflorescence was significantly reduced (Table 2).

The higher fruit set observed in Alq plants could be favoured by the inhibition of the fruit AZ (Pineda et al., 2010). According to Cuartero and Muñoz (1999), the inhibition of the fruit AZ could avoid the 'drop of developing fruit' often observed under salinity. In addition to the role played in fruit setting, auxin operates as a brake of fruit abscission (reviewed by Roberts et al., 2002). Interestingly, one possible role for CKs in fruit development is to modulate auxin biosynthesis and/ or polar auxin transport to prevent flower abscission (Matsuo et al., 2012). Some MADS-box genes such as JOINTLESS and $M A C R O C A L Y X(M C)$ regulate pedicel AZ development and activate the auxin-mediated pathway to prevent flower abscission (Mao et al., 2000; Nakano et al., 2012). It is known that JOINTLESS and MC interact with ALQ-TAGL1 (Leseberg et al., 2008; Giménez et al., 2016). In addition, ectopic expression of the ALQ-TAGL1 gene promotes down-regulation of JOINTLESS in Alq sepals (Pineda et al., 2010). Then, the increase in endogenous CKs in Alq plants could play, in concert with auxins, an important role in the inhibition of the pedicel AZ associated with the interaction between the Alq mutation and both JOINTLESS and MC genes.

The maintenance of agricultural productivity under unfavourable stress conditions is an important goal in order to meet growing food demand through sustainable agriculture (Cuartero et al., 2010; Pineda et al., 2012). Recently, Klap et al. (2017) reported that SlAGL6 loss of function results in fertilization-independent fruit set, improving fruit production under heat stress conditions that usually affect pollen viability and the fertilization process. Here, by evaluating long-term production, we show that $A l q$ plants are able to maintain fruit yield under moderate salinity conditions based on a higher fruit set rate. Notably, when only the ovary-derived fruits are taken into account, Alq plants set $59 \%$ more fruits and gave $39 \%$ higher yield than the WT under saline conditions. Taking into account both sepal- and ovary-derived fruits, Alq plants set $74 \%$ more fruits and had $75 \%$ higher yield than the WT in stress conditions.

In summary, our results reveal that increased expression of the ALQ-TAGL1 gene in the Alq mutant promotes early fruit set (i.e. prior to anthesis) which could be due to the increase in the content of endogenous CKs and the decrease in the level of $\mathrm{ABA}$ in pre-anthesis. In addition, the Alq mutant undergoes a much higher fruit set rate than the WT. Importantly, the ability of the Alq mutation to increase the fruit set rate allows for the maintenance of fruit yield under moderate salinity conditions.

\section{Supplementary data}

Supplementary data are available at $J X B$ online.

Fig. S1. In vitro assays of pollen viability in WT and Alq plants. 
Fig. S2. Red fruits developed from emasculated flowers of the Alq mutant.

Fig. S3. Total RNA quality assessment using denaturing agarose/formaldehyde gel electrophoresis.

Fig. S4. Expression analyses of GA biosynthesis genes and GA inactivation genes.

Fig. S5. Expression analyses of auxin response transcription factors.

Fig. S6. Expression analyses of ethylene- and senescence-related genes.

Fig. S7. Fruits produced in inflorescences of WT and Alq plants under control and salt stress conditions.

Table S1. Level of facultative parthenocarpy in WT and Alq plants.

Table S2. Weight and seed number of fruits obtained from self-pollination by hand or reciprocal backcrosses between WT and Alq flowers.

Table S3. Ovary- and calyx-derived fruit set from flowers emasculated at the pre-anthesis stage of WT and Alq plants.

Table S4. Relative comparison of reproductive development in the salt-treated plants (with respect to untreated plants) in the WT and Alq.

Table S5. Primers used for real-time quantitative PCR assays.

\section{Acknowledgements}

This work was supported by the research grants AGL2015-64991C3-3-R and AGL2015-64991-C3-1-R from the Spanish Ministry of Economy and Competitiveness (MINECO/FEDER). The PhD grant to CRA (BES-2013-063778) was funded by the Spanish Ministry of Economy and Competitiveness. The authors thank Dr Isabel López-Diaz and Dr Esther Carrera for their help in hormone quantification carried out at the Plant Hormone Quantification Service, IBMCP,Valencia, Spain. The authors thank David Harry Rhead for reviewing the manuscript in the English language. The author(s) declare that they have no competing interests.

\section{References}

Asahira T, Takeda Y, Nishio T, Hirabayashi M, Tsukamoto Y. 1967. Studies on fruit development in tomato. I. Ovule development and content of diffusible auxin in synthetic auxin- and gibberellin-induced parthenocarpic tomato fruits in relation to their development. Memoirs of the Research Institute for Food Science, Kyoto University 28, 47-74.

Azzi L, Deluche C, Gévaudant F, Frangne N, Delmas F, Hernould M, Chevalier C. 2015. Fruit growth-related genes in tomato. Journal of Experimental Botany 66, 1075-1086.

Bassel GW, Mullen RT, Bewley JD. 2008. Procera is a putative DELLA mutant in tomato (Solanum lycopersicum): effects on the seed and vegetative plant. Journal of Experimental Botany 59, 585-593.

Brukhin V, Hernould M, Gonzalez N, Chevalier C, Mouras A. 2003. Flower development schedule in tomato Lycopersicon esculentum cv. sweet cherry. Sexual Plant Reproduction 15, 311-320.

Busi MV, Bustamante C, D'Angelo C, Hidalgo-Cuevas M, Boggio SB, Valle EM, Zabaleta E. 2003. MADS-box genes expressed during tomato seed and fruit development. Plant Molecular Biology 52, 801-815.

Carmi N, Salts Y, Dedicova B, Shabtai S, Barg R. 2003. Induction of parthenocarpy in tomato via specific expression of the rolB gene in the ovary. Planta 217, 726-735.

Carrera E, Ruiz-Rivero O, Peres LE, Atares A, Garcia-Martinez JL. 2012. Characterization of the procera tomato mutant shows novel functions of the SIDELLA protein in the control of flower morphology, cell division and expansion, and the auxin-signaling pathway during fruit-set and development. Plant Physiology 160, 1581-1596.

Chevalier C. 2007. Cell cycle control and fruit development. Annual Plant Review 32, 269-293.

Cuartero J, Bolarín MC, Moreno V, Pineda B. 2010. Molecular tools for enhancing salinity tolerance in plants. In: Jain SM, Brar DS, eds. Molecular techniques in crop improvement. New York: Springer, 373-405.

Cuartero J, Fernández-Muñoz R. 1999. Tomato and salinity: a review. Scientia Horticulturae 78, 83-125.

de Jong M, Mariani C, Vriezen WH. 2009a. The role of auxin and gibberellin in tomato fruit set. Journal of Experimental Botany 60, 1523-1532.

de Jong M, Wolters-Arts M, Feron R, Mariani C, Vriezen WH. $2009 \mathrm{~b}$. The Solanum lycopersicum auxin response factor 7 (SIARF7) regulates auxin signaling during tomato fruit set and development. The Plant Journal 57, 160-170.

Ding J, Chen B, Xia X, Mao W, Shi K, Zhou Y, Yu J. 2013. Cytokinininduced parthenocarpic fruit development in tomato is partly dependent on enhanced gibberellin and auxin biosynthesis. PLoS One 8, e70080.

Ficcadenti N, Sestili S, Pandolfini T, Cirillo C, Rotino GL, Spena A. 1999. Genetic engineering of parthenocarpic fruit development in tomato. Molecular Breeding 5, 463-470.

Ghanem M, van Elteren J, Albacete A, Quinet M, Martínez-Andújar C, Kinet JM, Pérez-Alfocea F, Lutts S. 2009. Impact of salinity on early reproductive physiology of tomato (Solanum lycopersicum) in relation to a heterogeneous distribution of toxic ions in flower organs. Functional Plant Biology 36, 125-136.

Gillaspy G, Ben-David H, Gruissem W. 1993. Fruits: a developmental perspective. The Plant Cell 5, 1439-1451.

Giménez E, Castañeda L, Pineda B, Pan IL, Moreno V, Angosto T, Lozano R. 2016. TOMATO AGAMOUS1 and ARLEQUIN/TOMATO AGAMOUS-LIKE1 MADS-box genes have redundant and divergent functions required for tomato reproductive development. Plant Molecular Biology 91, 513-531.

Giménez E, Pineda B, Capel J, Antón MT, Atarés A, Pérez-Martín F, García-Sogo B, Angosto T, Moreno V, Lozano R. 2010. Functional analysis of the Arlequin mutant corroborates the essential role of the Arlequin/ TAGL1 gene during reproductive development of tomato. PLoS One $\mathbf{5}$, e14427.

Giovannoni J, Nguyen C, Ampofo B, Zhong S, Fei Z. 2017. The epigenome and transcriptional dynamics of fruit ripening. Annual Review of Plant Biology 68, 61-84.

Goetz M, Hooper LC, Johnson SD, Rodrigues JC, Vivian-Smith A, Koltunow AM. 2007. Expression of aberrant forms of AUXIN RESPONSE FACTOR8 stimulates parthenocarpy in Arabidopsis and tomato. Plant Physiology 145, 351-366.

Hoagland DR, Arnon DI. 1950. The water-culture method for growing plants without soil. Agricultural Experiment Station Circular 347. Berkeley, CA: College of Agriculture, University of California.

Itkin M, Seybold H, Breitel D, Rogachev I, Meir S, Aharoni A. 2009. TOMATO AGAMOUS-LIKE 1 is a component of the fruit ripening regulatory network. The Plant Journal 60, 1081-1095.

Jasinski S, Tattersall A, Piazza P, Hay A, Martinez-Garcia JF, Schmitz G, Theres K, McCormick S, Tsiantis M. 2008. PROCERA encodes a DELLA protein that mediates control of dissected leaf form in tomato. The Plant Journal 56, 603-612.

Joubès J, Phan TH, Just D, Rothan C, Bergounioux C, Raymond P, Chevalier C. 1999. Molecular and biochemical characterization of the involvement of cyclin-dependent kinase A during the early development of tomato fruit. Plant Physiology 121, 857-869.

Kataoka K, Uemachi A, Yazawa S. 2003. Fruit growth and pseudoembryo development affected by uniconazole, an inhibitor of gibberellin biosynthesis, in pat-2 and auxin-induced parthenocarpic tomato fruits. Scientia Horticulturae 98, 9-16.

Klap C, Yeshayahou E, Bolger AM, Arazi T, Gupta SK, Shabtai S, Usadel B, Salts Y, Barg R. 2017. Tomato facultative parthenocarpy results from SIAGAMOUS-LIKE 6 loss of function. Plant Biotechnology Journal 15, 634-647.

Kumar M, Singh VP, Arora A, Singh N. 2014. The role of abscisic acid (ABA) in ethylene insensitive Gladiolus (Gladiolus grandiflora Hort.) flower senescence. Plant Physiology 36, 151-159. 
Leseberg CH, Eissler CL, Wang X, Johns MA, Duvall MR, Mao L. 2008. Interaction study of MADS-domain proteins in tomato. Journal of Experimental Botany 59, 2253-2265.

Liu S, Zhang Y, Feng Q, Qin L, Pan C, Lamin-Samu AT, Lu G. 2018. Tomato AUXIN RESPONSE FACTOR 5 regulates fruit set and development via the mediation of auxin and gibberellin signaling. Scientific Reports $\mathbf{8}$, 2971.

Mao L, Begum D, Chuang HW, Budiman MA, Szymkowiak EJ, Irish EE, Wing RA. 2000. JOINTLESS is a MADS-box gene controlling tomato flower abscission zone development. Nature 406, 910-913.

Mariotti L, Picciarelli P, Lombardi L, Ceccarelli N. 2011. Fruit-set and early fruit growth in tomato are associated with increases in indoleacetic acid, cytokinin, and bioactive gibberellin contents. Journal Plant Growth Regulation 30, 405-415.

Marsch-Martínez N, Ramos-Cruz D, Irepan Reyes-Olalde J, LozanoSotomayor P, Zúñiga-Mayo VM, de Folter S. 2012. The role of cytokinin during Arabidopsis gynoecia and fruit morphogenesis and patterning. The Plant Journal 72, 222-234.

Martí C, Orzáez D, Ellul P, Moreno V, Carbonell J, Granell A. 2007. Silencing of DELLA induces facultative parthenocarpy in tomato fruits. The Plant Journal 52, 865-876.

Matsuo S, Kikuchi K, Fukuda M, Honda I, Imanishi S. 2012. Roles and regulation of cytokinins in tomato fruit development. Journal of Experimental Botany 63, 5569-5579.

Mazzucato A, Cellini F, Bouzayen M, Zouine M, Mila I, Minoia S Petrozza A, Picarella ME, Ruiu F, Carriero F. 2015. A TILLING allele of the tomato Aux/IAA9 gene offers new insights into fruit set mechanisms and perspectives for breeding seedless tomatoes. Molecular Breeding $\mathbf{3 5}$, 22.

Mazzucato A, Taddei AR, Soressi GP. 1998. The parthenocarpic fruit (pat) mutant of tomato (Lycopersicon esculentum Mill.) sets seedless fruits and has aberrant anther and ovule development. Development 125, 107-114.

McAtee P, Karim S, Schaffer R, David K. 2013. A dynamic interplay between phytohormones is required for fruit development, maturation, and ripening. Frontiers in Plant Science 4, 79.

Muños S, Ranc N, Botton E, et al. 2011. Increase in tomato locule number is controlled by two single-nucleotide polymorphisms located near WUSCHEL. Plant Physiology 156, 2244-2254.

Nakano T, Kimbara J, Fujisawa M, Kitagawa M, Ihashi N, Maeda H, Kasumi T, Ito Y. 2012. MACROCALYX and JOINTLESS interact in the transcriptional regulation of tomato fruit abscission zone development. Plant Physiology 158, 439-450.

Nitsch LM, Oplaat C, Feron R, Ma Q, Wolters-Arts M, Hedden P, Mariani C, Vriezen WH. 2009. Abscisic acid levels in tomato ovaries are regulated by LeNCED1 and SICYP707A1. Planta 229, 1335-1346.

Pineda B, García-Avellán JO, Antón T, et al. 2012. Genomic approaches for salt and drought stress tolerance in tomato. In: Tuteja N, Gill SS, Tiburcio AF, Tuteja R, eds. Improving crop resistance to abiotic stress. Weinheim: Wiley-VCH Verlag and Co. KGaA, 1085-1110.

Pineda B, Giménez-Caminero E, García-Sogo B, Antón MT, Atarés A, Capel J, Lozano R, Angosto T, Moreno V. 2010. Genetic and physiological characterization of the Arlequin insertional mutant reveals a key regulator of reproductive development in tomato. Plant \& Cell Physiology 51, 435-447.
Roberts JA, Elliott KA, Gonzalez-Carranza ZH. 2002. Abscission, dehiscence, and other cell separation processes. Annual Review of Plant Biology 53, 131-158.

Rojas-Gracia P, Roque E, Medina M, et al. 2017. The parthenocarpic hydra mutant reveals a new function for a SPOROCYTELESS-like gene in the control of fruit set in tomato. New Phytologist 214, 1198-1212.

Rotino GL, Acciarri N, Sabatini E, et al. 2005. Open field trial of genetically modified parthenocarpic tomato: seedlessness and fruit quality. BMC Biotechnology 5, 32.

Ruan YL, Patrick JW, Bouzayen M, Osorio S, Fernie AR. 2012. Molecular regulation of seed and fruit set. Trends in Plant Science 17, 656-665.

Seo M, Jikumaru Y, Kamiya Y. 2011. Profiling of hormones and related metabolites in seed dormancy and germination studies. Methods in Molecular Biology 773, 99-111.

Serrani JC, Fos M, Atarés A, García-Martínez JL. 2007. Effect of gibberellin and auxin on parthenocarpic fruit growth induction in the cv MicroTom of tomato. Journal Plant Growth Regulation 26, 211-221.

Shabtai S, Salts Y, Kaluzky G, Barg R. 2007. Improved yielding and reduced puffiness under extreme temperatures induced by fruit-specific expression of rolB in processing tomatoes. Theoretical and Applied Genetics 114, 1203-1209.

Shinozaki Y, Ezura H, Ariizumi T. 2018. The role of ethylene in the regulation of ovary senescence and fruit set in tomato (Solanum lycopersicum). Plant Signaling \& Behavior 13, e1146844.

Shinozaki Y, Hao S, Kojima M, et al. 2015. Ethylene suppresses tomato (Solanum lycopersicum) fruit set through modification of gibberellin metabolism. The Plant Journal 83, 237-251.

Tadiello A, Pavanello A, Zanin D, Caporali E, Colombo L, Rotino GL, Trainotti L, Casadoro G. 2009. A PLENA-like gene of peach is involved in carpel formation and subsequent transformation into a fleshy fruit. Journal of Experimental Botany 60, 651-661.

Ueta R, Abe C, Watanabe T, Sugano SS, Ishihara R, Ezura H, Osakabe Y, Osakabe K. 2017. Rapid breeding of parthenocarpic tomato plants using CRISPR/Cas9. Scientific Reports 7, 507.

Vrebalov J, Pan IL, Arroyo AJ, et al. 2009. Fleshy fruit expansion and ripening are regulated by the tomato SHATTERPROOF gene TAGL1. The Plant Cell 21, 3041-3062.

Vriezen WH, Feron R, Maretto F, Keijman J, Mariani C. 2008. Changes in tomato ovary transcriptome demonstrate complex hormonal regulation of fruit set. New Phytologist 177, 60-76.

Wang H, Jones B, Li Z, Frasse P, Delalande C, Regad F, Chaabouni S, Latché A, Pech JC, Bouzayen M. 2005. The tomato Aux/IAA transcription factor IAA9 is involved in fruit development and leaf morphogenesis. The Plant Cell 17, 2676-2692.

Wang $H$, Schauer N, Usadel B, Frasse P, Zouine M, Hernould M, Latché A, Pech JC, Fernie AR, Bouzayen M. 2009. Regulatory features underlying pollination-dependent and -independent tomato fruit set revealed by transcript and primary metabolite profiling. The Plant Cell 21, 1428-1452.

Winer J, Jung CK, Shackel I, Williams PM. 1999. Development and validation of real-time quantitative reverse transcriptase-polymerase chain reaction for monitoring gene expression in cardiac myocytes in vitro. Analytical Biochemistry 270, 41-49. 